\title{
Yabancı Dil Olarak Çince Öğretiminde Dinleme Dersi Öğretimi Sanatı*
}

\author{
对外汉语听力教学艺术
}

\section{Xiaoying HUANG / Çeviri: Lale AYDIN TUNÇ ${ }^{1}$ ()}

*Çevirisi yapılan bu kitap bölümü, 2008 ylında Pekin Dil ve Kültür Üniversitesi tarafindan basilan 《对外汉语课堂教学艺术》(Duiwai Hanyu Ketang Jiaoxue Yishu) adlı kitabın 152-162. sayfaları arasında yer almaktadır.

ORCID: L.A.T. 0000-0002-7144-2004

Sorumlu yazar/Corresponding author: Lale Aydın Tunç (Arş. Gör. Dr.),

İstanbul Üniversitesi, Edebiyat Fakültesi, Doğu Dilleri ve Edebiyatları Bölümü, Çin Dili ve Edebiyatı Anabilim Dalı, İstanbul, Türkiye E-posta: lale.aydin@istanbul.edu.tr

Başvuru/Submitted: 01.02 .2021 Revizyon Talebi/Revision Requested: 15.02.2021

Son Revizyon/Last Revision Received: 22.02.2021

Kabul/Accepted: 23.02 .2021

Atıf/Citation: Huang, Xiaoying. "Yabancı Dil Olarak Çince Öğretiminde Dinleme Dersi Öğretimi Sanatı," çeviren Lale Aydın Tunç̧". Sarkiyat Mecmuas! - Journal of Oriental Studies 38 (2021), 193-206

https://doi.org/10.26650/jos.872003
Dinleme dersi yabancı dil olarak Çince öğretiminde başlı başına beceri eğitimi dersidir. Modern toplumların ikinci dil öğrenmesindeki ana motivasyonu iletişim ihtiyacından kaynaklanmaktadır. Bu nedenle ikinci dilin eğitim amacı, öğrencilere mutlak surette iletişim kurabilecek yeteneği kazandırmaktır. İkinci dilin girdi (input) yeteneği (dinleme ve okuma), çıktı (output) yeteneğinin (konuşma ve yazma) ön koşulu ve temelidir. Eğer karşı tarafın ne dediği bile anlaşılmıyorsa, iletişim etkinliği imkansız hale gelir. Dinleme dersini planlamamızdaki esas nokta budur. Yabancı dil olarak Çince dinleme öğretiminin nasıl gerçekleştirilmesi gerektiği meseleleri üzerine farklı fikirler mevcut; kimileri görsel ve işitsel öncülüğü savunurken, kimileri dinleme ve konuşma birliğini savunmaktadır. Her birinin kendine özgü sebeplerinin olduğunu söyleyebiliriz. Bu çalışma, dinleme dersinin bağımsız bir ders türü olduğu öncülüğüne dayanmakta ve yabancı dil olarak Çince dinleme öğretiminin temel kuralları ile uygulama sanatını incelemektedir.

\section{Dinleme Dersi Öğretimi Sanatının Temel Kuralları}

\section{a) Uygun Ders Aracı Seçilmeli}

Dinleme dersinde dinleme uygulaması temel alınmalıdır. Ders aracında yer alan kelimelerin çoğunluğu öğrencilerin önceden öğrendiği kelimeler olmalıdır. Kelime ile yeni gramer kalıplarının fazla olması uygun değildir. Aksi halde, ders muhtemelen yoğun okuma dersi haline gelir. Dolayısıyla ders 
aracı, paralel olarak kullanılan ders setlerinden seçilmelidir. Bu tarz bir ders kitabı genellikle diğer derslerde öğrenilen kelime ve dil bilgisi kalıplarını büyük ölçüde tekrar eder ve dinleme dersindeki engelleri azaltır. Eğer set kaynağı kullanılmazsa, öğretmen derste kullandığı araca oldukça hakim olmalı ve zor kısımları belirlemelidir. Uygulamaların da kanıtladığı gibi, öğrencilerin karşılaştığı zorlukları doğru bir şekilde kavramak, iyi bir dinleme dersinin önemli ön koşullarından biridir.

\section{b) Öğrencilerin Anlayabileceği Akışta İlerlemeli}

Amerikalı psikodilbilim uzmanı Stephen Krashen, ikinci dilin kurallarından biri olan "i+1" kuralını ortaya koymuştur. "i” öğrencilerin var olan dil seviyesidir, "1" var olan seviyesine ek olarak bir adım daha ilerlemesidir. " $i+1$ ” kuralı, öğrencilerin var olan dil seviyesine ek olarak gelişiminin girdisidir. ${ }^{1}$ Bu kural dinleme dersine uyarlandığında, öğrencilerin gerçek seviyesinden yola çıkılmalı, öğrencilerin dinlediklerini anlamaları ve kavramaları sağlanmalıdır. Ayrıca sırasıyla ve kademe kademe ilerlenmelidir. Parça dinleme alıştırması yapmaya yeni başlamış öğrencilere, tek seferde art arda çok uzun dinleme parçaları verilmesi uygun değildir. Ardından gelen sorulara göre parça birkaç bölüme ayrılabilir. Bir bölüm dinlenip, bir soru cevaplanabilir. Daha sonra tamamı iki kez tekrar dinletilmeli ve tüm parçanın içeriği anlaşıldıktan sonra sorular cevaplandırılmalıdır.

\section{c) Öğrencilere Gerekli Yönergeler Verilmeli}

Bazı öğretmenler dinleme dersinde ses kaydını açıp öğrencilere dinletir. İlk sefer anlamadıklarında tekrar dinletir. Eğer üç dört kez dinlettiğinde öğrenciler hala anlamazsa direkt olarak cevabı söyler. Bazı öğretmenler ise öğrencilerin ön hazırlık yaptıktan sonra derse gelmelerini ister. Bu iki çeşit yöntem de dinleme dersinin gerekliliğini olumsuz etkilemektedir. Çünkü öğrenciler ses kaydını kendileri evde de dinleyip cevaplara bakabilir. Öğretmen öğrencilerin kelime bilgisine hakim olmalıdır. Eğer öğrenciler dinleme materyalindeki bazı temel kelimeleri daha önce öğrenmedilerse, dinlemeden önce öğretmen mutlaka açıklama yapmalıdır. Örneğin; Eğer öğrenciler, “报名者逾百万。“Kayıt yapanlar bir milyonu geçti.” Cümlesindeki “逾” “geçmek” kelimesini öğrenmedilerse, “报名的人有多少? ”“Kayıt yapan kaç kişi var?” sorusunu doğru cevaplayamazlar.

\section{d) Konuşma Dilindeki Ders Araçlarına Ăğırlık Verilmeli}

Dinleme dersinin amacı öğrencilerin dil iletişim becerisini geliştirmektir. Karşı tarafın ne dediğini anlarlarsa ancak gerçek anlamdaki dil iletişim becerisini gerçekleştirmiş olurlar. Dinleme araçları her ne kadar yazı dili ağırlıklı olsa da, başlangıç ve orta seviyeler için konuşma dili ağırlıklı kaynaklar kullanılmalıdır. İleri seviyeler için röportaj tarzı kaynaklar veya haber kaynakları seçilerek kullanılması uygun olacaktır.

\footnotetext{
1 Jia Guanjie, Waiyu Jiaoyu Xinlixue, Guangxi Jiaoyu Chubanshe, 1996, 9.
} 


\section{e) Dinleme Becerilerinin Geliştirilmesine Dikkat Edilmeli}

Dinleme dersi, ders kitabı içeriğini anlama amaçlı değil, öğrencilerin dinleme becerisini geliştirme amaçlıdır. Öncelikle ders kitabının tamamı konuşma ile sınırlı olamaz. Ayrıca gerçek hayattaki cümleler daima değişiklik gösterir, ders kitabındaki ile tamamen aynı olması imkansızdır. Birçok öğrencinin ön hazırlık yaparak derse gelmesi, dinleme dersinde dinleme becerilerinin iyi seviyede görünmesine rağmen, sınav esnasında konunun biraz değişmesiyle birlikte doğru cevap verememelerinin altında yatan sebeptir. Dinleme dersi, öğrencilerin ses kaydı aracılığıyla kavrama, dinleme sonrası taklit etme, mantıklı bağlantı kurarak tahmin etme, hızlı not alma, cümle kalıbı değiştirme, gereksiz olanı eleyip, gerekli olanı seçme (engelleri aşma) gibi yeteneklerini eğitmelidir.

\section{Dinleme Dersi Öğretiminin Öğretim Sanatı}

\section{a) Uygun Isınma}

Her ders aracında ilgili art alan bilgisi mevcuttur. Bazı öğrenciler bu bilgilere aşina iken, bazı öğrenciler yabancıdır. Bazı öğrenciler bu bilgileri daha yüzeysel seviyede tutarken, bazı öğrenciler hafızalarının daha derinlerinde tutar. Bilgiye yabancı olan öğrenciler için uygun bir açıklama yapılmalıdır. Bilgiyi hafızalarının derinlerinde tutan öğrenciler için de onları harekete geçirmek denenmelidir. Bu da, öğretmenin ders hazırlığı yaparken ses kaydı metnini uygun bir süreçle tamamlamasını gerektirir. Bunlardan birincisi, soruları cevaplarken öğrencilere engel teşkil edecek ana kelimeleri mutlaka bulmak gerektiğidir. Ayrıca bu engelleri yok edecek yol ve yönteme karar verilmelidir. İkincisi, kaynağın art alanı ile öğrencilerin bilgi haznesi arasındaki ilişkinin incelenmesi gerektiğidir. Daha sonra öğrencilerin kaynağı dinlemeden önce onlara uygun ön bilgi verme ya da açıklama yöntemine gerek olup olmadığına karar verilmelidir; yani uygun bir ısınma sağlanmalıdır. Isınmanın temel olarak iki çeşidi vardır: İlk çeşidi, dinleme içeriğine art alan hatırlatması yapmaktır. Resim kullanılabilir, soru sorulabilir, obje kullanılabilir vb. İkincisi, öğrencilere öncelikle aşina olduğu alternatif cevaplar sunulmalıdır. Aşina olduğu alternatif cevaplar öğrencilerin kaynaktaki konunun yönünü tahmin etmesini sağlar. Dolayısıyla bu da bir çeşit ısınmadır. Art alan hatırlatma yöntemi oldukça fazladır. Bir resim ya da görüntü gösterilebilir, bir obje kullanılarak içerikle alakası aktarılabilir, dinleme aracındaki konuyla alakalı soru sorulabilir ya da öğrenciye kendi yaşadığı deneyimi anlattırılabilir vb. Aşina olunan alternatif cevap yöntemi de tek çeşit değildir. Öğrencilerin kendilerinin okuması sağlanabilir, sırasıyla öğrencilere okutulabilir, öğretmen kendisi okuyabilir, öğretmen okurken öğrencilerin kitaba bakmaması söylenebilir. Art alan hatırlatması ya da aşina olunan alternatif cevap yöntemlerine ancak ders aracının içeriği incelendikten sonra karar verilmelidir.

\section{b) Kademeli Eleme}

Belirli bir soru türünün bazı alıştırmalarını yaparken kademeli eleme yöntemi kullanılmalıdır. Her dinlemeden sonra öğrencilerin tamamen anladığı sorular elenmelidir. Zorluk veya 
kolaylığından bağımsız olarak, her soruyu aynı sayıda dinletmek uygun değildir. Öğrencinin kararını hızlı bir şekilde öğrenmek için her öğrenciye üç ufak kart verilir. Kartın önüne ve arkasına $\mathrm{A}$ ve $\mathrm{B}$, diğer kartın önüne ve arkasına $\mathrm{C}$ ve $\mathrm{D}$, bir diğer kartın önüne ve arkasına $\times$ ve $\checkmark$ işaretleri yazılır. Her seçmeli soruyu veya doğru-yanlış sorusunu dinledikten sonra öğrencilerin kartı kaldırması ve kendi cevaplarını ifade etmeleri sağlanır. Bu yöntem öğretmenin öğrencilerden çok hızlı şekilde geri dönüş almasını sağlar. Elbette başka yöntem de kullanılabilir. Örneğin, öğrenciler el kaldırarak da cevap verebilirler.

\section{c) Soruya Göre Cevap Değerlendirmesi}

Bazı öğrenciler her ne kadar doğru cevap vermiş olsa da aslında bilinçsizce doğru cevap vermiştir. Bu yüzden öğretmen, sebebinin ne olduğu, doğru olan cevabın neden doğru olduğu, yanlış olan cevabın neden yanlış olduğu gibi fazladan sorular sormalıdır. Öğrenciler sıklıkla eleme yöntemini kullanarak doğru cevabı seçiyorlar, başka bir deyişle onlar sadece hangi cevabın yanlış olduğunu biliyorlar. Fakat geri kalanların neden doğru olduğunu bilmiyorlar. Soru sorarak zorlanılan noktaları daha net şekilde anlayabiliriz. Dikkat edilmesi gereken husus; tüm öğrencilere aynı soru sorulmamalıdır. Çünkü ancak bireysel sorular öğrencilerin tamamının anlayıp anlamadığını tespit edebilir.

\section{d) Zamanında Sorun Giderme}

Standart bir dinleme dersi kitabında her ünitede belli sayıda kelime listelenir. Fakat dinleme araçlarında öğrencilerin anlamadığı bazı kelime veya cümle kalıpları da ortaya çıkabilir. Ĕger bu kısım öğrencilerin direkt olarak soruyu anlamalarını, karar vermelerini etkiliyorsa ve zor aşacakları bir engele dönüşüyorsa, öğretmenin hemen sorunu çözmesi gerekir. Aksi durumda, defalarca dinletilse bile, öğrencilerin yine de kafaları karışır. Tabii öğrencilerin her kelimeyi mutlaka anlamalarını bekleyemeyiz. Çünkü dinleme dersinin görevlerinden biri de öğrencilerin "engeli aşma” yeteneğini geliştirmektir. Özellikle nispeten uzun parçalarda. Uyulması gereken kural; öğrencilerin sadece anlamadıkları için soruyu cevaplayamayacakları kelimeler, ancak yok edilmesi gereken engel sayılmalıdır. Eğer öğretmen öğrencileri çok iyi tanıyorsa, ders hazırlığı yaparken öğrenciler için "engel” sayılacak kelimeleri doğru şekilde bulabilir veya alternatif cevaplardan ya da dinleme metninden bunları bulabilir. Ders hazırlığı esnasında fark etmese bile bu kelimeleri ders sırasında mutlaka kesin ve hızlı şekilde bulur.

\section{Dinleme Dersi Öğretiminin Alıştırma Sanatı}

\section{a) Heceleri Ayırt Etme Alıştırmaları}

(1) İlk alıştırma ünlü ve ünsüz diktesidir. Öğrencilerden dinlediklerini sırasıyla tabloya işaretlemeleri istenir. Önce sıra arkadaşıyla karşılıklı kontrol ettirilir ve sonrasında öğretmen tekrar okuyarak yanlış yazdıkları yerleri düzelttirir. 
(2) Öğrencilere ünlülerden oluşan bir grup hece verilir. Öğretmen heceleri okurken, öğrencilerden bir yandan dinleyip bir yandan ünsüzleri yazmasını ister. Sonra ünsüzlerden oluşan bir grup hece verilir. Öğretmen heceleri okurken, öğrencilerden ünlüleri yazmasını ister.

(3) Öğrencilerin sıkça karıştırdığı ünlü ve ünsüzlerden oluşan hecelerden bir grup alıştırma verilmelidir. (Örneğin; “z, c, s”, “'zh, ch, sh”, “b, p”, “g, k”, “d, t”, “an, ang”, “en, eng” vb.) Öğretmen karışık bir sıra ile okumalı ve öğrencilerden tabloya sırasıyla yazmalarını istemelidir.

\section{b) Ses Tonları Alıştırmaları}

(1) Bir grup hece verilerek öğrencilerin hem dinleyip hem de ses tonlarını işaretlemeleri sağlanır.

(2) Öğrencilere her çeşit tondan heceler verilir. Dinletildikten sonra ses tonlarına göre ayırmaları istenir. Tek heceliler dört tona göre bir tarafta ve çok heceliler dört tona göre diğer tarafta gruplandirılabilir.

\section{c) Tonlama Alıştırması}

Öğretmen noktalama işaretlerini belirtmeksizin, yükselen ve alçalan tonlamalarda basit cümleler okur. Öğrenciler dinledikten sonra cümle sonuna soru işareti ya da nokta koyarlar. Buna ek olarak öğrencilerden el işaretleri ile alçalan ve yükselen tonları göstermeleri istenebilir.

\section{d) Vurgu Alıştırması}

Bir grup cümle verilir ve öğrenciler bir taraftan dinlerken bir taraftan vurgulanan kısımları sırasıyla işaretler. Buna ek olarak, öğretmen aynı cümlede farklı yerde vurgu yapabilir ve öğrenciler vurguya göre soru sorabilirler. Örneğin;

教师: “我明天一点去机场接朋友。”

Öğretmen: "Ben yarın saat birde havalimanına arkadaşımı karşılamaya gideceğim."

学生: “谁明天一点去机场接朋友?”

Öğrenci: "Yarın saat birde havalimanına arkadaşını karşılamaya kim gidecek?"

教师: “我旦天一点去机场接朋友。”

Öğretmen: "Ben yarın saat birde havalimanına arkadaşımı karşılamaya gideceğim.”

学生: “你哪天一点去机场接朋友?”

Öğrenci: "Sen hangi gün saat birde havalimanına arkadaşını karşılamaya gideceksin?"

教师: “我明天二点去机场接朋友。”

Öğretmen: "Ben yarın saat birde havalimanına arkadaşımı karşılamaya gideceğim." 
学生: “你明天几点去机场接朋友?”

Öğrenci: "Sen yarın saat kaçta havalimanına arkadaşını karşılamaya gideceksin?”

教师: “我明天一点去机场接朋友。”

Öğretmen: "Ben yarın saat birde havalimanına arkadaşımı karşılamaya gideceğim."

学生: “你明天一点去哪儿接朋友?”

Öğrenci: "Sen yarın saat birde arkadaşını karşılamaya nereye gideceksin?"

教师: “我明天一点去机场接朋友。”

Öğretmen: "Ben yarın saat birde havalimanına arkadaşımı karşılamaya gideceğim."

学生: “你明天一点去机场接谁?”

Öğrenci: "Sen yarın saat birde havalimanına kimi karşılamaya gideceksin?”

\section{e) Cümle Dinleme Alıștırmaları}

(1) Dinledikten sonra konuşma veya dinledikten sonra yazma alıştırması. Öğretmen bir cümle söyledikten sonra öğrencilerin bunu tekrar etmelerini veya yazmalarını ister.

(2) Soru cümlesini dinledikten sonra sözlü veya yazılı cevap verme.

A: 你学了多长时间的汉语?

B:

A: Ne kadar süre Çince öğrendin?

B:

(3) Dinlenen sorunun içeriğine göre cevap verme veya seçeneklerden doğru olanı seçme.

“他来中国半年了。”

"O Çin'e geleli yarım sene oldu."

问：他来中国多长时间了?

Soru: O Çin'e geleli ne kadar oldu?

Sözlü olarak cevaplanabileceği gibi aşağıdaki seçeneklerden de seçilebilir:
A. 六个月
B. 半天
C. 半年
B. Alt1 ay
B. Yarım gün
C. Sekiz sene 
(4) Sözcük seçerek boşluk doldurmaca. Cümle içerisinden bazı sözcükler çıkarılır, öğretmen cümleyi okur ve öğrenciler bu sözcükleri şıklardan seçerek boşlukları doldurur. Şıklar öğrencilerin ayırt etmesini zorlayan ve ses olarak birbirine yakın sözcükler olmalıdır. Örneğin:

他的...... 有毛病。（眼睛、眼镜）

Onun ...... rahatsız. (göz, gözlük)

(5) Bir grup cümle verilir ve öğretmen aynı sayıda cümle okur. Dinledikten sonra öğrencilerden her cümle için doğru/yanlış şeklinde seçim yapmaları istenir.

Öğrencilere aşağıdaki cümleler verilir:
A. 我不习惯吃中国菜。（ ）
B. 他买了一个杯子。（ ）

A. Ben Çin yemekleri yemeye alışık değilim. ( )

B. O bir bardak satın aldı. ( )

Öğretmen ise şu cümleleri okur:
A. 我不喜欢吃中国菜。
B. 他卖了一个杯子。
A. Ben Çin yemekleri yemeyi sevmem.
B. O bir bardak sattı.

(6) Dinleme sonrası uygulama. Örneğin, 教师: “请把书打开。”Öğretmen: “Lütfen kitabı açınız." dediğinde öğrenciler uygun fiili yerine getirir.

(7) Dinledikten sonra tahmin etme. Örneğin, 教师: “你听磁带的时候要用什 么? ”Öğretmen: “Kaset ne ile dinlenilir?” diye sorduğunda, 学生: “录音机。”Öğrenci: "Kaset çalar ile." diye cevaplar.

\section{f) Diyalog Dinleme Alıştırmaları}

(1) Dinleme sonrası boşluk doldurmaca. Dinlenilen içeriğe göre boşluklar uygun şekilde doldurulur. Boşluklarda, telefon numarası, herhangi bir şeyin fiyatı, oda numarası gibi rakamlar olabileceği gibi, millet adları, renkler ve zaman bildiren sözcükler olabilir.
$\mathrm{A}$ : 你是哪国人?
$\mathrm{B}$ : 我是……人。你呢?
$\mathrm{A}$ : 我是韩国人。你住在几楼? 
B: 我住……楼，……房间。

$\mathrm{A}$ : 你的电话号码是多少?

B:

A: Sen nerelisin?

B: Ben Ya sen?

A: Ben Koreliyim. Kaçıncı katta kalıyorsun?

B: ...... katta, ...... numaralı odada kalıyorum.

A: Telefon numaran kaç?

B:

(2) Doğru/yanlış alıştırması. Diyalog dinletildikten sonra öğrencilere verilen cevaplarla doğru/yanlış seçimi yaptırılır. Örneğin;

A: 这次你去北京出差, 应该顺便看看李老师。

B：我们经理让我办完事马上回来，恐怕没时间。

$A$ ：实在不行, 就算了。

$\mathrm{B}$ : 看情况再说吧。

A: Bu sefer iş için Pekin'e gitmişken Li Hoca'yı da ziyaret etmelisin.

B: Müdürümüz işim biter bitmez dönmemi söyledi. Korkarım vaktim olmayacak.

A: Gerçekten mümkün değilse boş ver gitsin.

B: Duruma göre bakarım artık.

Dinledikten sonra doğru/yanlış alıştırması:

1. A去北京看李老师。

2. 经理让 $A$ 马上去北京。

3. A和B都认识李老师。

4. A觉得去不去看李老师都行。

5. B 可能去看李老师。

1. A Pekin'e Li Hoca’yı görmeye gidiyor.

2. Müdür A'nın hemen Pekin'e gitmesini istiyor.

3. A ve B her ikisi de Li Hoca'yı tanıyor.

4. A Li Hoca'yı görse de olur, görmese de olur diye düşünüyor.

5. B Li Hoca'yı görmeye gidebilir. 
(3) Tek uygun cevabı bulma. Diyalog dinlendikten sonra içeriğe göre şıklardan en uygun olan seçilir. Örneğin:
A: 下周日小王结婚，你去吗？
B: 他的婚礼, 我怎么能不参加呢?

A: Gelecek pazar günü Wang evleniyor, sen gidecek misin?

B: Onun düğününe gitmemem olur mu hiç!

问：B的意思是：

Soru: B ne demek istiyor?

1. Ben onun düğününe kesinlikle gitmeyeceğim.

2. Ben onun düğününe belki giderim.

3. Ben onun düğününe kesin gideceğim.

4. Ben onun düğününe gidemem.

(4) Dinleme sonrası resim seçme. Ses kaydının içeriğine göre birkaç resim içerisinden doğru olan resim seçilir. Şu anda kullandığımız ders kaynaklarında bu tarz alıştırma oldukça azdır.

(5) Dinleme sonrası sıraya koyma. Verilen cümleler veya resimler dinleme sirasına göre siraya koyulur.

\section{g) Parça Dinleme Alıştırmaları}

(1) Dinleme sonrası kelime seçme. Ders kitabında yer alan ve almayan bazı kelime grupları verilir. Öğrencilerin bir yandan dinlerken bir yandan bu kelimeleri işaretlemeleri istenir. Verilen kelimeler parçadaki temel kelimeler olmalıdır. İki kez dinledikten sonra öğrenciler bu kelimelerden yola çıkarak parçayı büyük oranda anlarlar.

传说, 孟姜女刚结婚没几天, 丈夫就去修长城了。天越来越冷, 孟姜女给丈夫做 了一身棉衣, 要给丈夫送去。可是丈夫在哪儿呢? 她不知道, 她只知道长城在北方, 于是就一直往北走。走了好多天，才走到长城。他看见人就问认不认识她丈夫，问了 好多人, 才找到一个认识她丈夫的人, 可是这个人告诉她说, 修长城太累了, 她丈夫 到这不长时间就累死了。孟姜女听后十分悲伤, 坐在长城下哭了几天几夜。一天, 她 正哭着, 忽然, 长城倒了一大段, 露出了她死去的丈夫, 孟姜女悲伤极了, 跳进了大 海, 也死了。

“Efsaneye göre, Meng Jiang Hanım evlendikten birkaç gün sonra eşi Çin Seddi’ni onarmaya gider. Havalar gitgide soğuyunca Meng Jiang Hanım eşine bir hırka örer ve ona vermek için yola çıkar. Ama eşinin nerede olduğunu bilmez. Tek bildiği Çin Seddi'nin kuzeyde olduğudur. 
Bu yüzden kuzeye doğru ilerler. Günlerce yürür ve sonunda Çin Seddi’ne varır. Gördüğü insanlara eşini tanıyıp tanımadıklarını sorar. O kadar çok kişiye sorar ki sonunda eşini tanıyan biri çıkar. Ama bu kişi ona, Çin Seddi'ni onarmanın çok yorucu olduğunu ve eşinin buraya geleli çok geçmeden yorgunluktan öldüğünü söyler. Meng Jiang Hanım o kadar çok üzülür ki, Çin Seddi'nde oturup günlerce gecelerce ağlar. Bir gün o yine ağlarken Çin Seddi'nin bir bölümü aniden yıkılır ve ölen eşi görünür. Meng Jiang Hanım çok üzülür ve kendini denize atarak ölür."

Bu metne göre, aşağıdaki kelime grupları verilir:

结婚、好几年、丈夫、修长城、冬天、冷、一件、棉衣、送、北方、坐车、走、 问、很容易、找到、告诉、太累了、不长时间、痛苦、悲伤、哭、忽然、倒、到、 露出、跳进、水。

“Evlenmek, birkaç yıl, eş, Çin Seddi'ni onarmak, kış, soğuk, bir (adet), hırka, vermek, kuzey, arabaya binmek, yürümek, sormak, çok kolay, bulmak, söylemek, çok yorgun, kısa bir zaman, keder, üzgün, ağlamak, aniden, yıkılmak, varmak, görünmek, atlamak, su.”

Öğrenciler ilk dinlemeden sonra anladıkları kelimelerin altını çizerler. İkinci dinlemeden sonra altını çizdikleri kelimelerden önce ya da sonra temel kelimeleri eklerler. Üçüncü dinlemeden sonra başka kelimeler ekleyebilirler. En sonunda öğrencilerden, bu kelimelere göre metinde ne anlatıldığgnı söylemeleri istenir.

(2) Dinleme sonrası soru- cevap. Dinlenen metnin içeriğine göre bazı sorular sorulur ve öğrencilerin cevaplamaları istenir. Yukarıdaki metne göre, dinleme öncesi ve sonrası aşağıdaki sorular cevaplanır:

1. 孟姜女结婚不长时间, 家里发生了一件什么事?

2. 孟姜女为什么要去找丈夫?

1. Meng Jiang Hanım evlendikten birkaç gün sonra ne olur?

2. Meng Jiang Hanım neden kocasını aramaya gider?

(3) Dinleme sonrası doğru/yanlış alıştırması. Dinlenilen metne göre, verilen ifadelerin doğru/yanlış olduğu belirlenir.

1. 孟姜女结婚不长时间丈夫就去修长城了。

2. 孟姜女十分想念她的丈夫, 所以去长城了。 
1. Meng Jiang Hanım evlendikten birkaç gün sonra eşi Çin Seddi’ni onarmaya gider.

2. Meng Jiang Hanım eşini çok özlediği için Çin Seddi’ne gider.

(4) Dinleme sonrası doğru cevabı seçme. Birkaç soru ve şık verilir. Dinleme sonrası şıklardan en uygun olan cevap seçilir.

1. 孟姜女结婚多长时间，丈夫去修长城的?
A. 没几年
B. 才几天
C. 几个月

1. Meng Jiang Hanım evlendikten ne kadar süre sonra eşi Çin Seddi'ni onarmaya gider?
A. Birkaç yıl olmadan
B. Birkaç gün
C. Birkaç ay

2. 孟姜女为什么要去长城?
A. 送棉衣
B. 想丈夫
C. 天冷了

2. Meng Jiang Hanım neden Çin Seddi'ne gider?
A. Hırkayı vermek için
B. Eşini özlediği için
C. Hava soğuduğu için

(5) Dinleme sonrası resim çizme. Yol güzergahı, adres krokisi, oda krokisi vb. olabilir. Örneğin, öğrenciler kendi aralarında birbirlerine tatil planlarını veya okuldan kaldıkları yere olan güzergahı sorarlar. Karşı tarafın söylediklerini dinlerken bir yandan da krokisini çizerler.

(6) Dinleme sonrası tablodaki boşlukları doldurma. Tabloda bir ya da birden fazla yerin hava durumu tahmini ya da ürün miktarı ile fiyatları verilebilir. İçerisinden bir bölümü çıkarılarak, kalan bölümlerin öğrencilerden dinleyerek boşlukları doldurmaları istenir.

\begin{tabular}{|l|c|c|c|c|}
\hline Yer Adı/Hava Durumu & & Şanghay & Harbin & \\
\hline Rüzgar Hızı & $\begin{array}{c}2-3 \text { şiddetinde kısmi } \\
\text { doğu rüzgarı }\end{array}$ & & & $\begin{array}{c}4-5 \text { şiddetinde } \\
\text { kuzeybatı rüzgarı }\end{array}$ \\
\hline Hava Sıcaklığı & & $16^{\circ} \mathrm{C}-24^{\circ} \mathrm{C}$ & $6^{\circ} \mathrm{C}-12{ }^{\circ} \mathrm{C}$ & \\
\hline
\end{tabular}

(7) Dinleme sonrası eşleştirme. Dinlenilen içeriğe göre iki veya daha fazla cümle grupları verilir. Dinleme sonrası temel cümleler eklenir. Örneğin:

我爸爸是足球迷, 如果有精彩的足球比赛, 他可以不吃饭、不睡觉。他喜欢看报, 每天早上起床后第一件事就是看报。我妈妈除了爱打扫房间, 还爱看电视连续剧。我 
哥哥打篮球很拿手, 他还特别喜欢看书。我最爱听流行歌曲和打乒乓球。我妹妹呢, 喜欢弹琴、唱歌、跳舞。对了，她还喜欢穿漂亮的衣服。

"Babam futbol hayranıdır. Eğer heyecanlı bir maç varsa yemek yemediği ve uyumadığı zamanlar olur. Gazete okumayı da sever. Her sabah uyandığında ilk yaptığı şey gazete okumaktır. Annem temizlik yapmayı sevmek dışında, TV dizisi izlemeyi sever. Ağabeyim basketbol oynamada ustadır ve ayrıca kitap okumaya bayılır. Ben en çok popüler müzik dinlemeyi ve masa tenisi oynamayı severim. Kız kardeşim ise gitar çalmaktan, şarkı söylemekten ve dans etmekten hoşlanır. Tabii bir de güzel kıyafetler giymekten hoşlanır."

Dinledikten sonra uygun ifadeleri eşleştirerek birleştiriniz.

$\begin{array}{lll}\text { 足球迷 } & \text { 我 } & \text { 打篮球拿手 } \\ \text { 爱看电视连续剧 } & \text { 妹妹 } & \text { 爱打乒乓球 } \\ \text { 喜欢穿漂亮的衣服 } & \text { 妈妈 } & \text { 喜欢看报 } \\ \begin{array}{l}\text { 听流行歌曲 } \\ \text { 特别喜欢看书 }\end{array} & \text { 哥哥 } & \text { 喜欢弹琴、唱歌 } \\ & \text { 爸爸 } & \text { 爱打算房间 } \\ \text { Futbol hayranıdır } & & \\ \text { TV dizisi izlemeyi sever } & \text { Ben } & \text { Basketbolda ustadır } \\ \text { Güzel kıyafetler giymeyi sever } & \text { Kız kardeş } & \text { Masa tenisi oynamayı sever } \\ \text { Popüler müzik dinler } & \text { Ağabey } & \text { Gazete okumayı sever } \\ \text { Kitap okumaya bayılır } & \text { Baba } & \text { Gitar çalmayı, şarkıyı̈ sölemeyi sever } \\ & & \text { Temizlik yapmayı sever }\end{array}$

(8) Dinleme sonrası sıraya koyma. Dinlenilen içeriğe göre karışık sırada bir grup cümle verilir ve dinleme sonrası öğrencilerden en baştan sıralama yapmaları istenir.

昨天是星期天, 我没有课。吃了早饭以后, 我去书店买了几本书。午饭是在食堂 吃的。下午在校门口买了两张电影票, 想请我的朋友王刚一起去看。晚饭后我给王 刚打电话, 我们是八点一刻在电影院门口见面的, 电影八点半开演, 是一部很有意 思的中国片。

“Dün günlerden pazardı, dersim yoktu. Kahvaltı yaptıktan sonra kitabevine gidip birkaç kitap aldım. Öğle yemeğini yemekhanede yedim. Öğleden sonra okulun girişinden iki sinema bileti aldım. Arkadaşım Wang Gang’’ davet etmek istiyordum. Akşam yemeğinden sonra Wang Gang'a telefon ettim. Sekizi çeyrek geçe sinemanın girişinde buluştuk. Film sekiz buçukta başladı. Çok güzel bir Çin filmiydi.” 
Dinledikten sonra aşağıdaki cümleler numaralandırılarak sıraya koyulur.

吃早饭
买电影票
去书店
吃午饭
给王刚打电话
吃完饭
看电影

Kahvaltı yapmak

Sinema bileti almak

Kitabevine gitmek

Öğle yemeği yemek

Wang Gang'a telefon etmek

Akşam yemeği yemek

Film izlemek

(9) Dinleme sonrası tekrar etmek. Hikaye yönü güçlü olan ilginç ve kısa hikayeler seçilmesi daha faydalı olur. Birkaç kez dinletildikten sonra, öğrencilerden hikayeyi tekrar etmeleri istenir. Öğrenciler bir yandan dinleyip bir yandan temel kelimeleri not almalıdırlar.

(10) Bir yandan dinleyip bir yandan izleme. Görsel-işitsel ders de denilebilir. Haberler, talk şov, tartışma programı, film veya dizi izlenebilir. Bu daha çok ileri seviyelere yönelik bir alıştırmadır. İzlemeye başlamadan önce, izleme esnasında ve sonrasında, öğretmen öğrencilere gerekli açıklamayı yapmalıdır ve görev tanımlarını net olarak planlayarak en sonunda öğrencilerin durumlarını kontrol etmelidir.

\section{Dinleme Dersi Öğretiminde Sık Karşılaşılan Sorunlar}

a) Önem Derecesini Ayırmaksızın Genel Dinleme Yapılması

İki çeşit durum vardır: Bunlardan birincisi, öğrencilerden metindeki paragrafın her cümlesinin ve kelimesinin anlamalarını beklemektir. Dinleme dersi öğrencilerin sorun çözme becerisini geliştirmelidir. Öğrenciler dinlediği metnin tamamını anlamasa bile, bu durum içeriğin ana temasını anlamalarını etkilemez. İkincisi, metnin tamamının aynı sayıda dinletilmesidir. Ders süresi oldukça kıymetlidir, eğer öğrenci dinletileni ilk seferde anladıysa ikinci kez dinletilmesine gerek yoktur. Kalan vakit, kilit noktalardaki zor kısımlar için kullanılmalıdır. Kaynaktaki her bölümdeki metinde öğrencilerin mutlaka bilmesi gereken bazı kelimeler vardır ve bu kelimeler eğitimdeki ana hedef olmalıdır. Önem derecesi ayırmaksızın genel dinleme yapmaktan ve eşit derecede odaklanmaktan mutlaka kaçınılmalıdır. 


\section{b) Öğretmenin Öğrenci Yerine Cevap Vermesi}

Ses kaydı sonrası soru sorulduğunda, bir öğrenci cevap veremediğinde ya da yanlış yanıt verdiğinde öğretmen direkt olarak cevabı söylemektedir. Dinleme dersinde cevabı öğrencilerin vermeleri sağlanmalıdır. Cevap veremediklerinde ya da yanlış cevap verdiklerinde öğretmen bunun sebebini belirlemelidir. Herhangi bir kelimeyi mi bilmediklerini, aşina olmadıkları bir cümle yapısı mı olduğunu ya da herhangi bir kelimenin özel bir kullanımını mı anlamadıklarını tespit etmelidir. Sorun çözüldükten sonra tekrar dinletilerek öğrencilerin anlamaları sağlanmalıdır.

\section{c) Sadece Sonuca Odaklanıp, Süreci Önemsememe}

Öğrencilerin basit bir şekilde doğru/yanlış standart soru şeklini cevaplamasıyla onların gerçekten anlayıp anlamadıkları veya yüzde kaç anladıkları ihmal edilmektedir. Bazı öğretmenler öğrencilere toplu şekilde soru sormaya alışıktırlar ve yalnızca bir iki öğrencinin doğru cevap vermesiyle bir sonraki soruya geçerler. Aslında bazı öğrenciler cevabı biliyormuş gibi davranmaktadır, kimi zaman da cevabın neden o cevap olduğunu anlamazlar. Öğretmen listeden karışık şekilde öğrencilere soru sormalıdır ve gerçekten anlayıp anlamadıklarını, öğrencilerin yüzde kaçının anladığııı, yüzde doksanından fazlasının anladığından emin olduktan sonra yeni bir içerik dinletmeye devam etmelidir.

\section{d) Öğrencilerin Seviyelerini Bilmeden, Dinlemenin Gereksiz Yere Tekrar Edilmesi}

Öğretmenin, öğrencilerin seviyesine hakim olmaması, onların hangi kelime, gramer veya cümle yapılarında zorlandıklarını veya bilmedikleri noktaları tam olarak anlayamamasına yol açmaktadır. Bu da gereksiz yere çok kez dinleme yapılmasına sebep olmaktadır. Hatta bir bölüm metin defalarca dinletilse bile sonunda öğrenci yine anlamayacak ve boşu boşuna çok fazla zaman harcanacaktır. İçeriği anlamayan öğrenciler için, öğretmen sorunun nerede olduğunu çok iyi bilmelidir ve öğrencileri zamanında yönlendirerek gerekli yönergeleri vermelidir. 